\title{
Challenges in the codevelopment of companion diagnostics
}

Therapeutics harnessing the power of personalized medicine have the potential to revolutionize healthcare. Companion diagnostics are critical to this goal and are increasingly relied upon to ensure the effective, safe development and use of a personalized therapeutic. Companion diagnostics are the focus of several recent regulatory guidance documents; the drug-diagnostic codevelopment process has become increasingly relevant and necessary. Despite this, the promise of companion diagnostics has not been fully realized and there are multiple difficulties that still need resolution. The path to codevelop a successful companion diagnostic with its complementary drug is complex, fragmented and fraught with several challenges. In this article, we discuss the logistic, strategic business, regulatory and financial challenges involved in drug-companion diagnostic codevelopment.

\section{KEYWORDS: codevelopment companion diagnostics drug-diagnostic personalized medicine therapeutic}

The goal of personalized medicine, to effectively customize diagnosis, treatment and prevention of disease to one's genetic composition, is one that has been known and sought for many years. Increasingly, molecular companion diagnostics based on one's inherited or somatic biomarkers are desired to ensure the effective, safe development and application of a personalized drug. This has been reflected in several recent guidance documents from regulatory organizations worldwide, and in a number of instances, the use of a companion diagnostic has been required or recommended prior to administration of a personalized therapeutic.

There have been a number of successes in personalized medicine, but not as many as one might expect based on the historical level of interest [1]. Proposed regulatory documents have attempted to address this shortfall, and in doing so have identified the drug-diagnostic codevelopment process as critical to the success of personalized medicine. Unfortunately, the codevelopment process poses several challenges. Potential barriers are: a relatively low probability of success after a scientific discovery is made; navigating various development objectives for different drugs, targeting appropriate markets and users; the lack of clear regulatory and policy guidance; and partnership challenges between research and diagnostic cultures. Consequently, pharmaceutical and diagnostic companies may be less motivated to invest the substantial amount of time and resources needed to create a successful personalized therapeutic.

\section{The promise \& power of personalized medicine}

The field of personalized medicine evolved from the discipline of pharmacogenetics, essentially expanding upon the goal of identifying the right treatment, at the right dose, for the right disease/ patient $[2,3]$. Utilizing a stratified approach and identifying groups of patients based on certain biologic characteristics or biomarkers has the potential to be more efficient and effective while reducing undesirable drug interactions and side effects [4].

Recently, the interest in personalized medicine has increased substantially. From a 2011 PubMed search using the term 'personalized medicine', the number of scientific publications on the subject showed an exponential growth in the period 1999-2010, from approximately 0-5 to 450, respectively [4]. In 2006, there were 13 prominent examples of personalized medicine drugs, treatments and diagnostics products available [101]; in 2011, that number increased to 72 [102].

The personalized medicine market in the USA was estimated to be US $\$ 232$ billion in 2009 [103]. The core diagnostic and therapeutic segment of the market comprised primarily of pharmaceutical, medical device and diagnostics companies was estimated at US $\$ 24$ billion and expected to grow by $10 \%$ annually, reaching US $\$ 42$ billion by 2015 [103]. More evidence of a growing interest in personalized medicine is detailed in TABLE 1. In addition, molecular diagnostics represents one of the fastest growing segments of the

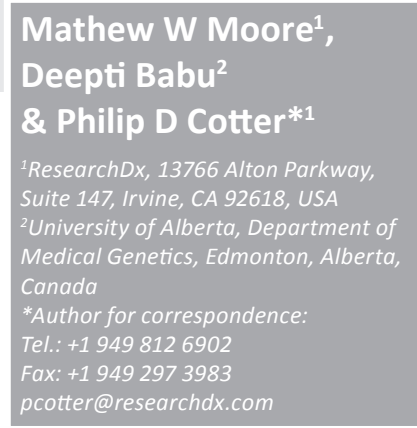

Future $\because \%$ 


\section{Table 1. Statistics demonstrating growing scientific, medical and economic interests in personalized medicine.}

\section{Example}

Number of prominent examples of personalized medicine drugs, treatments and diagnostics products available in 2006

Number of prominent examples of personalized medicine drugs, treatments and diagnostics products available in 2011

Percentage of marketed drugs with a companion diagnostic in 2011

Percentage of marketed drugs that inform or recommend genetic testing for optimal treatment

Number of pharmacogenomic biomarkers that are included on US-FDA approved drug labels

Portion of all treatments in late clinical development that rely on biomarker data

Portion of all treatments in early clinical development that rely on biomarker data

Portion of all treatments in preclinical development that rely on biomarker data

Amount of all biopharmaceutical companies surveyed that require all compounds in development to have a biomarker in 2011

Percentage increase in personalized medicine investment by industry over the last 5 years

Estimated personalized market size in 2009

Estimated personalized market size in 2015

Estimated molecular diagnostics market size in 2009

Estimated molecular diagnostics market size in 2015

Data taken from $[101,103]$.

\begin{tabular}{lr} 
Statistic & Ref. \\
\hline 13 & {$[101]$} \\
\hline 72 & {$[102]$} \\
\hline $1 \%$ & {$[104]$} \\
\hline $10 \%$ & {$[114]$} \\
\hline 33 & {$[114]$} \\
\hline $30 \%$ & {$[115]$} \\
\hline $50 \%$ & {$[115]$} \\
\hline $60 \%$ & {$[115]$} \\
\hline $30 \%$ & {$[104]$} \\
\hline $75 \%$ & {$[115]$} \\
\hline US $\$ 225-232$ & {$[103]$} \\
\hline billion & \\
\hline US $\$ 344-452$ & {$[103]$} \\
billion & \\
\hline US $\$ 3$ billion & {$[103]$} \\
\hline US $\$ 7$ billion & {$[103]$} \\
\hline & \\
\hline
\end{tabular}

US $\$ 37$ billion US market for in vitro diagnostics (IVDs) [103]. Even with this growth potential, approximately only $1 \%$ of marketed therapeutics had a companion diagnostic in 2011 [104]. Even after considering that companion diagnostics are not appropriate for all therapeutics, this percentage is lower than one would expect based upon interest documented in the market research. This suggests the difficulty of developing a successful companion diagnostic.

\section{Companion diagnostics \& how they impact personalized medicine}

Successful companion diagnostics have been used in several modalities (Box 1). One use is to stratify patients who will (or will not) respond to a particular drug prior to its administration, or identify those who should not be treated with the drug because of a high risk for adverse events [5]. For example, FISH analysis of the $A L K$ gene rearrangements is required to select patients for treatment with the oral ALK inhibitor crizotinib (Xalkori $\left.{ }^{\circledR}\right)$ in non-small-cell lung cancer (NSCLC) [6-8]. Specifically in oncology, predictive biomarkers can address aspects of host toxicity or of direct anticancer efficacy (by monitoring treatment effectiveness) [9]. For example, quantitative real-time PCR analysis of $B C R-A B L 1$ fusion transcripts is used to monitor imatinib mesylate $\left(\right.$ Gleevec $\left.^{\circledR}\right)$ treatment in patients with chronic myeloid leukemia [10].

Another important use of companion diagnostics is to customize drug dosage based on metabolism biomarker status, such as in warfarin dosing. Individuals with $C Y P 2 C^{*} 2$ and $C Y P 2 C 9^{*} 3$ genotypes produce an enzyme with reduced capacity (by 30 and $80 \%$, respectively) to metabolize warfarin [5]. Those with VKORC1 1639G $>\mathrm{A}$ genotypes produce an enzyme with approximately $50 \%$ reduced metabolism capacity. Dosing using traditional methods can lead to delayed and elevated systemic warfarin levels, often leading to an increased bleeding risk [11]. As such, reduced warfarin dosages may be recommended for those with specific genotypes. Although not the standard of care, warfarin dosage can be calculated after stratification using a molecular companion diagnostic and algorithm incorporating a patient's CYP2C9 and $V K O R C 1$ genotypes [105], and estimating the therapeutic dose in patients new to warfarin [12].

\section{Regulatory responses}

Recent regulatory agency commentaries acknowledge the value of companion diagnostics and the slow output of personalized therapeutics from pharmaceutical companies. The US FDA, Health Canada and the EMA have either mandated or recommended in several cases that biomarker 
testing be performed prior to prescribing certain drugs [102]. While this opinion was consistent between the regulatory agencies, documents still lacked clear guidance about how to navigate the numerous steps in the development process.

A February 2011 revision of the European Commission's directive on IVDs indicated, "...the competence of the European Medicine Agency should be extended to pharmacogenomics, as the IVD medical device has an impact on the health outcome of the medicinal product and then the analytical and clinical validity of the IVD medical device should be part of the assessment of the benefit-risk assessment of the medicinal product" [106]. The importance of companion diagnostics was reiterated here, but again without clear recommendations about their development.

Subsequently, in July 2011, the FDA issued draft guidance for comment purposes on the development of IVD companion diagnostic devices. The draft guidance indicated that: "The results of the IVD companion diagnostic device will be essential for the safe and effective use of the therapeutic product and its use will be stipulated in the labeling of the therapeutic product." It was noted that: "With some exceptions [the] FDA does not believe it may approve a novel therapeutic product or new therapeutic product indication for use with an IVD companion diagnostic if the IVD companion diagnostic is not approved or cleared for that indication" [107].

The FDA draft guidance also recommended that: "In most circumstances, if use of an IVD companion diagnostic device is essential for the safe and effective use of a therapeutic product, [it and its] therapeutic product should be approved or cleared contemporaneously by [the] FDA for the use indicated in the therapeutic product labeling" [107]. This was a clear statement from a regulatory agency that it may not approve a product unless its companion diagnostic was also approved or cleared, emphasizing the need for codevelopment. Furthermore, the document helpfully outlined the codevelopment steps in a flow diagram; it also suggested various pathways that might be taken. Unfortunately, guidance documents that only apply to a small subset of cases in the personalized genomics field also hinder its progress. Fortunately, in late 2011, the FDA declared an intent to produce guidances on enrichment strategies in clinical drug development [108], so further clarification should be forthcoming.

There are several examples of required companion diagnostics. The original example, from 1998 , is in the oncology sector. Detection of
HER-2/neu protein amplification by a molecular cytogenetic companion diagnostic is used to identify patients more likely to respond to trastuzumab (Herceptin ${ }^{\circledR}$ ) in breast (and now gastric) cancers [13-16].

In late 2011, Health Canada required the use of a companion diagnostic to identify patients with metastatic melanoma containing the V600E mutation in the $B R A F$ gene [17-20], prior to treatment with vemurafenib (Zelboraf ${ }^{\circledR}$ ). The commentary reiterated that: "The parallel development of this companion diagnostic together with a specific targeted therapy marks a new era of personalized health care in which patients are selected for treatment on the basis of well-validated molecular biomarkers" [18].

A 2007 example outside the oncology sector is with the use of maraviroc (Selzentry ${ }^{\circledR}$ ) in patients with HIV/AIDS. A highly sensitive tropism assay is required to identify those with CCR5-tropism HIV-1, who are then candidates for maraviroc, in conjunction with other retroviral agents [21,22].

In these cases, companion diagnostics were deemed critical for appropriate stratification of patients before drug administration. More examples are detailed in TaвıE 2.

\section{Developing a companion diagnostic}

The components required to create a companion diagnostic are outlined in Figure 1. Many of these require specific expertise and experience, from early scientific discovery and biomarker development, to regulatory filing and approval, and finally manufacturing.

\section{Drug-diagnostic codevelopment}

The key to effectively introduce a successful personalized therapeutic to a market is codevelopment of the drug and its companion diagnostic. Ideally, a companion diagnostic will be studied in parallel with its drug in Phase I or II [23]. This scenario is not always possible, due to safety of a drug being tested prior to its efficacy.

Box 1. Different uses of companion diagnostics.

- Stratify appropriate patients for whom a drug would be effective

- Stratify patients for whom a drug would not be effective

- Stratify patients in whom a drug could induce serious adverse events

- Identify appropriate drug dosage

- Monitor drug treatment and effectiveness 


\section{Table 2. Examples of companion diagnostics required or recommended by the US FDA.}

\begin{tabular}{|c|c|c|c|c|}
\hline Drug & Manufacturer & Indication(s) & $\begin{array}{l}\text { Companion } \\
\text { diagnostic }\end{array}$ & $\begin{array}{l}\text { US FDA } \\
\text { status }\end{array}$ \\
\hline $\begin{array}{l}\text { Vesanoid }^{\circledR} \text { (retinoid), } \\
\text { Trisenox }{ }^{\circledR} \text { (arsenic } \\
\text { trioxide) }\end{array}$ & $\begin{array}{l}\text { Roche, Cell } \\
\text { Therapeutics, } \\
\text { Inc. }\end{array}$ & $\begin{array}{l}\mathrm{t}(15 ; 17) \text { chromosome translocation or } P M L / R A R \alpha \text { gene } \\
\text { expression in acute promyelocytic leukemia }\end{array}$ & $P M L / R A R \alpha$ analysis & Required \\
\hline $\begin{array}{l}\text { Herceptin }^{\circledR} \\
\text { (trastuzumab), } \\
\text { Tykerb }^{\circledR} \text { (lapatinib) }\end{array}$ & $\begin{array}{l}\text { Genentech, } \\
\text { GlaxoSmithKline }\end{array}$ & $\begin{array}{l}\text { Overexpression of HER-2 in metastatic breast cancer } \\
\text { tumor cells }\end{array}$ & $\begin{array}{l}\text { HercepTest }{ }^{\mathrm{TM}} \text { for } \\
\text { HER-2/neu receptor }\end{array}$ & Required \\
\hline Gleevec $^{\circledR}$ (imatinib) & Novartis & $\begin{array}{l}\text { Philadelphia chromosome-positive }\left(B C R-A B L 1^{+}\right) \text {chronic } \\
\text { myeloid leukemia in chronic phase }\end{array}$ & $B C R-A B L 1$ analysis & Required \\
\hline Gleevec $^{\circledR}$ (imatinib) & Novartis & $\begin{array}{l}\text { PDGFR gene rearrangements in MDS/myeloproliferative } \\
\text { diseases }\end{array}$ & PDGFR analysis & Required \\
\hline $\begin{array}{l}\text { Bexxar }^{\circledR} \\
\text { (tositumomab) }\end{array}$ & Corixa & Hodgkin's lymphoma cells expressing CD20 antigen & $\begin{array}{l}\text { CD20 antigen } \\
\text { analysis }\end{array}$ & Required \\
\hline $\begin{array}{l}\text { Erbitux }^{\circledR} \\
\text { (cetuximab), } \\
\text { Vectibix }{ }^{\circledR} \\
\text { (panitumumab) }\end{array}$ & $\begin{array}{l}\text { Eli Lilly, } \\
\text { Amgen }\end{array}$ & $\begin{array}{l}\text { Overexpression of EGFR in metastatic colorectal cancer } \\
\text { tumors cells }\end{array}$ & $\begin{array}{l}\text { DakoCytomation } \\
\text { EGFR pharmDx }{ }^{\mathrm{TM}} \\
\text { expression assay } \\
\text { (Dako) }\end{array}$ & Required \\
\hline $\begin{array}{l}\text { Revlimid }^{\circledR} \\
\text { (lenalidomide) }\end{array}$ & $\begin{array}{l}\text { Celgene } \\
\text { Corporation }\end{array}$ & $\begin{array}{l}\text { Chromosome } 5 q \text { deletion associated with transfusion- } \\
\text { dependent anemia, due to low- or intermediate-1-risk } \\
\text { MDS, with/without additional cytogenetic abnormalities }\end{array}$ & $5 q$ deletion & Required \\
\hline Spryce ${ }^{\circledR}$ (dasatinib) & $\begin{array}{l}\text { Bristol-Myers } \\
\text { Squibb }\end{array}$ & $\begin{array}{l}\text { Philadelphia chromosome-positive acute lymphoblastic } \\
\text { leukemia with resistance or intolerance to prior therapy }\end{array}$ & $B C R-A B L 1$ analysis & Required \\
\hline $\begin{array}{l}\text { Ontak }^{\circledR}(\text { denileukin } \\
\text { diftitox })\end{array}$ & $\begin{array}{l}\text { Eisai Medical } \\
\text { Research }\end{array}$ & $\begin{array}{l}\text { Expression of CD25 component of IL-2 receptor in } \\
\text { persistent or recurrent cutaneous T-cell lymphoma }\end{array}$ & $\begin{array}{l}\text { CD25 expression } \\
\text { assay }\end{array}$ & Required \\
\hline Xalkori ${ }^{\circledR}$ (crizotinib) & Pfizer & $\begin{array}{l}\text { ELM4-ALK translocation-positive advanced or } \\
\text { metastatic non-small-cell lung cancer }\end{array}$ & $\begin{array}{l}\text { ELM4-ALK } \\
\text { translocation }\end{array}$ & Required \\
\hline $\begin{array}{l}\text { Zelboraf }{ }^{\circledR} \\
\text { (vemurafenib) }\end{array}$ & $\begin{array}{l}\text { Genentech, } \\
\text { Roche }\end{array}$ & $\begin{array}{l}\text { BRAF V600E mutation in unresectable or metastatic } \\
\text { melanoma }\end{array}$ & $\begin{array}{l}\text { BRAF V } 600 \mathrm{E} \\
\text { mutation }\end{array}$ & Required \\
\hline $\begin{array}{l}\text { Selzentry } \\
\text { (maraviroc) }\end{array}$ & Pfizer & $\begin{array}{l}\text { Treatment of CCR5-tropic HIV in adults only, in } \\
\text { combination with other antiretroviral agents }\end{array}$ & $\begin{array}{l}\text { TrofileTM (Monogram } \\
\text { Biosciences) tropism } \\
\text { assay for CCR5 } \\
\text { receptor }\end{array}$ & Required \\
\hline $\begin{array}{l}\text { Depakote }^{\circledR} \\
\text { (valproic acid) }\end{array}$ & $\begin{array}{l}\text { Abbott } \\
\text { Laboratories }\end{array}$ & $\begin{array}{l}\text { Treatment of bipolar disorder, depression, seizures, } \\
\text { autism, chronic pain with neuropathy and migraine } \\
\text { headaches. Hyperammonemic encephalopathy } \\
\text { (sometimes fatal) has been reported following initiation } \\
\text { of valproic acid therapy in patients with urea cycle } \\
\text { disorders, particularly ornithine OTC }\end{array}$ & $\begin{array}{l}\text { Metabolic and/or } \\
\text { molecular testing for } \\
\text { urea cycle disorders }\end{array}$ & Recommended \\
\hline $\begin{array}{l}\text { Coumadin }^{\circledR} \\
\text { (warfarin) }\end{array}$ & Various & $\begin{array}{l}\text { Anticoagulant used to reduce the risk for or treat } \\
\text { thrombosis, or as secondary prophylaxis to reduce the } \\
\text { risk for embolism. Those with certain mutations in } \\
\text { CYP2C9 and VKORC1 CYP450 enzymes metabolize } \\
\text { warfarin differently }\end{array}$ & $\begin{array}{l}\text { CYP2C9 and VKORC1 } \\
\text { genotyping }\end{array}$ & Recommended \\
\hline $\begin{array}{l}\text { Lipitor }^{\circledR} \\
\text { (atorvastatin) }\end{array}$ & Pfizer & $\begin{array}{l}\text { Treatment of hypercholesterolemia (familial and } \\
\text { nonfamilial). Those with homozygous and heterozygous } \\
\text { familial hypercholesterolemia need to receive } \\
\text { specific doses }\end{array}$ & $\begin{array}{l}\text { LDLR, } A P O B \text { and } \\
\text { PCSK9 mutation } \\
\text { analysis (for } \\
\text { autosomal dominant } \\
\text { forms) }\end{array}$ & Recommended \\
\hline $\begin{array}{l}\text { Tegretol }^{\circledR} \\
\text { (carbamazepine) }\end{array}$ & Various & $\begin{array}{l}\text { Treatment of seizures. Severe dermatologic reactions are } \\
\text { associated with } H L A-B{ }^{*} 1502 \text { allele, found in some Asian } \\
\text { patients }\end{array}$ & $\begin{array}{l}\text { HLA-B*1502 } \\
\text { genotyping }\end{array}$ & Recommended \\
\hline
\end{tabular}




\section{Table 2. Examples of companion diagnostics required or recommended by the US FDA (cont.).}

\begin{tabular}{|c|c|c|c|c|}
\hline Drug & Manufacturer & Indication(s) & $\begin{array}{l}\text { Companion } \\
\text { diagnostic }\end{array}$ & $\begin{array}{l}\text { US FDA } \\
\text { status }\end{array}$ \\
\hline $\begin{array}{l}\text { Pegasys }^{\circledR} \\
\text { (peginterferon } \alpha-2 a \text { ) }\end{array}$ & Genentech & $\begin{array}{l}\text { Treatment of chronic hepatitis C infection with } \\
\text { compensated liver disease. A SNP near the gene } \\
\text { encoding IFN- } \lambda-3(I L-28 B) \text { is associated with variable } \\
\text { sustained virological response rates }\end{array}$ & IL-28B genotyping & Recommended \\
\hline $\begin{array}{l}\text { Ziagen }^{\circledR} \\
\text { (abacavir) }\end{array}$ & GlaxoSmithKline & $\begin{array}{l}\text { Antiretroviral treatment of HIV. Patients who carry the } \\
H L A-B * 5701 \text { allele are at high risk for experiencing a } \\
\text { hypersensitivity reaction to abacavir }\end{array}$ & $\begin{array}{l}H L A-B * 5701 \\
\text { genotyping }\end{array}$ & Recommended \\
\hline $\begin{array}{l}\text { Aralen }^{\circledR} \\
\text { (chloroquine) }\end{array}$ & Various & $\begin{array}{l}\text { Antiparasitic treatment of malaria; can also } \\
\text { be used to treat lupus. Increased risk of hemolysis } \\
\text { when administered to patients with G6PD } \\
\text { deficiency }\end{array}$ & $\begin{array}{l}\text { Metabolic and/or } \\
\text { molecular testing for } \\
\text { G6PD deficiency }\end{array}$ & Recommended \\
\hline
\end{tabular}

In addition, companion diagnostic development may not always be useful until some time has gone by in the drug discovery period. Guidance documents from multiple regulatory agencies have attempted to outline the steps in the creation of companion diagnostics, and the complexity of the drug-diagnostic codevelopment process.

In June 2010, the EMA issued a reflection paper to outline suggested steps involved in the codevelopment of a new pharmacogenomic biomarker and the relevant assay(s) [109].

In its 2011 draft guidance, the FDA expanded on this to say: "Ideally, a therapeutic product and its corresponding IVD companion diagnostic device would be developed contemporaneously, with the clinical performance and clinical significance of the IVD companion diagnostic device established using data from the clinical development program of the corresponding therapeutic product..." [107]. Suggested codevelopment steps are outlined in Figure 2. Unfortunately, no guidance document is explicit on how this process should be implemented.

\section{Traditional partners for drug development \& approval}

Outsourcing options for pharmaceutical companies are widely available and commonly utilized

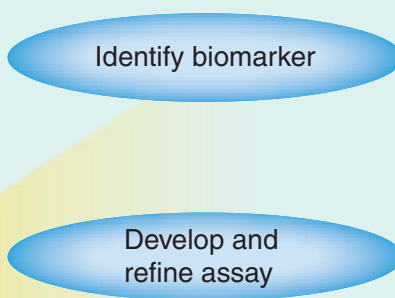

Companion diagnostic

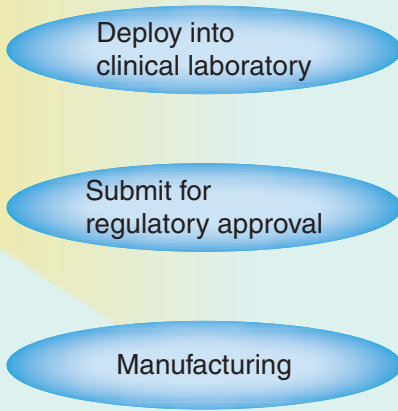

- DNA/RNA
- Protein
- Metabolite targets

- Screening assay

- Predictive marker screen

- Final marker selection

- Assay and platform selection

- Final kit design
- Multicenter prospective meta-analysis study
- File appropriate regulatory documents by deadlines

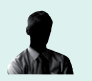

Clinical laboratories

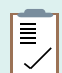

Regulatory consultants

Contract manufacturing

Figure 1. Typical components required to develop a companion diagnostic, separate from drug development. This is not applicable to laboratory-developed 'home brew' tests, such as the CCR5 tropism assay. 


\section{Drug R\&D}
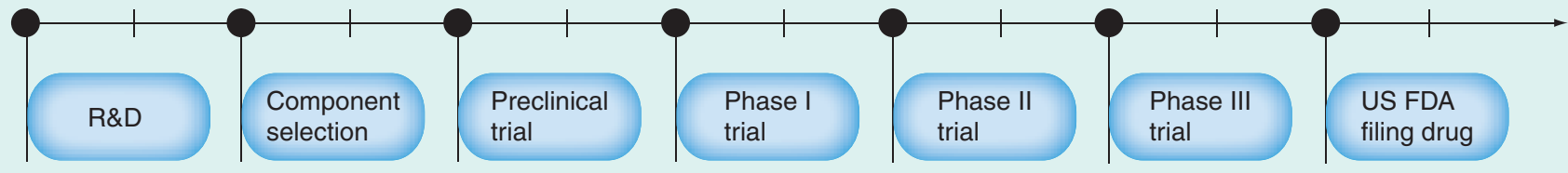

\section{Diagnostics component of clinical trial}

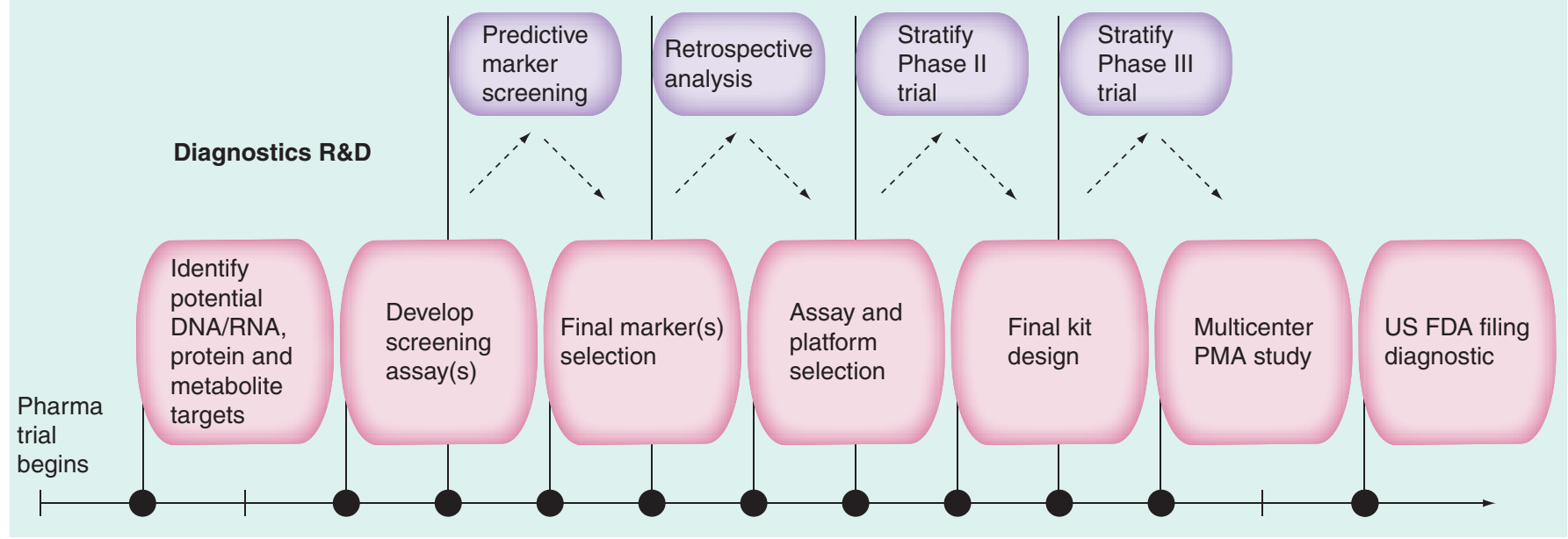

Figure 2. Proposed codevelopment of pharmaceuticals and companion diagnostics.

Pharma: Pharmaceutical; PMA: Prospective meta-analysis.

in the traditional drug development and approval process. Common choices are contract research organizations (CROs) and diagnostics companies. CROs provide efficient, cost-effective solutions to conduct clinical research. They can offer assistance with drug development, preclinical research, clinical research and clinical trial management. In addition, their focus and expertise is on operational efficiency and support of clinical trials for pharmaceuticals. This is evidenced by the Association of Clinical Research Organizations (ACRO) fact sheet, which states: "In 2008, the average ACRO member company worked on nearly 400 medications in development" [110]. CROs offer a complete solution for large drug companies developing traditional therapeutics. By contrast, diagnostics companies specialize in the development and manufacturing of diagnostic tests and equipment. Unlike a CRO, a diagnostic company's primary expertise is the development of internal pipeline products. Compared with drug development, the diagnostic industry is traditionally influenced by quite different driving forces. Diagnostic companies typically develop fewer products, with a higher percentage of successful launches than a similar drug-development comparator.

\section{Challenges in companion diagnostic codevelopment}

The components of companion diagnostic development require specific expertise rarely found in a single organization, introducing several challenges. These are compounded by the fact that an effective companion diagnostics codevelopment process does not currently exist, or is rudimentary at best. Key challenges fall into four broad categories (Figure 3).

\section{Strategic business challenges}

Similarly, strategic business challenges can complicate the path to development of a successful companion diagnostic. The large diagnostic company typically has innate conflicts of interest and other motivations. For example, large diagnostic partners usually have their own product lines and assay platforms. As a result, they naturally may be motivated to direct diagnostics development toward an internal technology platform to make the most of internal synergies and increase efficiency. However, that platform may not be the best choice for the new companion diagnostic and ultimately, their pharmaceutical partner. This can cost the pharmaceutical company time, resources and 
revenue; the choice of an assay platform also affects deployment into, and acceptance by, the end user clinical laboratories that may offer the test in the market.

A recent example illustrates challenges related to business partnerships. Rearrangements of the $A L K$ gene have been reported in patients with NSCLC [8,24]. Patients with advanced NSCLC containing $A L K$ rearrangements show a positive response to ALK-targeted therapy (crizotinib [Xalkori]) [6-8], while patients without the $A L K$ rearrangement showed a poor response thus making the companion diagnostic to identify $A L K$ rearrangements essential to drug administration.

As The Wall Street Journal reported, codevelopment of Xalkori and its companion diagnostic was strategically problematic [25]. Pfizer (the drug's developer and manufacturer) partnered with the diagnostics company Abbott Molecular to develop a molecular companion diagnostic to analyze $A L K$ in tumor tissue. Researchers between the companies reportedly had difficulties working together early on, which hampered initial development. In addition, Abbott Molecular reportedly resisted Pfizer's request to train commercial clinical laboratories in advance of FDA approval because: "It was concerned that those trained would forget how to conduct the assay while waiting for the drug and test to go on sale" [25]. Abbott Molecular may have delayed training because it did not want to risk an expenditure of resources prior to an FDA approval. Ultimately, Xalkori and its companion diagnostic test kit were granted FDA approval simultaneously, but not before several delays and difficulties were experienced in the process. The $A L K$ companion diagnostic (a FISH-based assay) has an advantage in that it utilizes a technology that can be performed in many laboratories.

Pharmaceutical and diagnostic companies have partnered successfully. But as with business partnerships outside the personalized medicine field, they need to be robust - particularly regarding trust, harmonized goals and clear communication at all levels - to help ensure a successful outcome.

\section{Regulatory challenges}

As noted previously, the CRO's expertise is in operational efficiency of clinical trials for pharmaceuticals. This clinical trial experience may be attractive to pharmaceutical companies looking to outsource this function, but few CROs have experience in IVD development, manufacture and medical device (companion diagnostic) validation trials, as well as experience in navigating regulatory recommendations and requirements.

Pharmaceutical companies want to ensure that clinical trials conducted for development of a companion diagnostic are run in an environment that ensures quick translation to the clinical setting after marketing launch. Delays may be introduced because of regulatory requirements. Therefore, many are turning to appropriately licensed and accredited clinical laboratories. This necessitates partnering with a laboratory possessing and maintaining those credentials and regulatory consulting expertise, which many traditional diagnostics companies and CROs do not offer.

\section{- Financial challenges}

Codevelopment of a therapeutic and companion diagnostic is associated with uncertainty and risk. Utilizing extensive new biologic tests increases the complexity and cost of the drug development process [26]. Unlike the pharmaceutical development industry, where there is an understanding that a large number of potential drugs will fail clinical studies (and that revenues will be derived from a very small cohort of successful drugs), no such precedent currently exists in the diagnostic development space. While the codevelopment of a diagnostic and therapeutic is advantageous from a cost and efficiency perspective, the number of late-stage compound failures is high. This makes a codevelopment agreement even less financially desirable from a diagnostic perspective, due to the significant risk and high cost involved in developing diagnostics for drugs that never receive regulatory approval. Thus, diagnostic companies may be hesitant to share the financial burden and partner for companion diagnostic development.

In addition, end users such as physicians and other healthcare providers have expressed

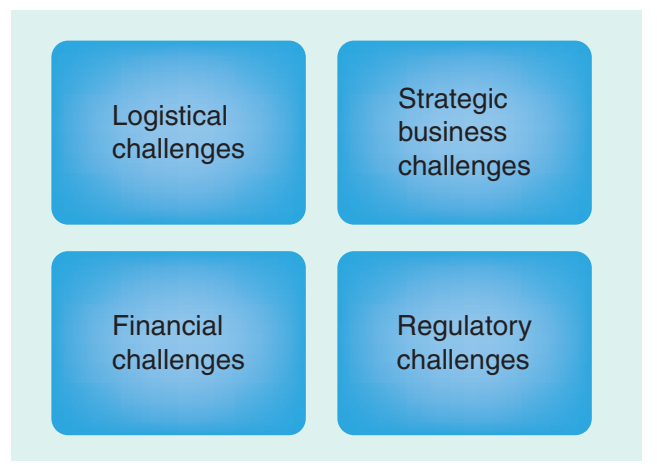

Figure 3. Challenges associated with the codevelopment of companion diagnostics. 


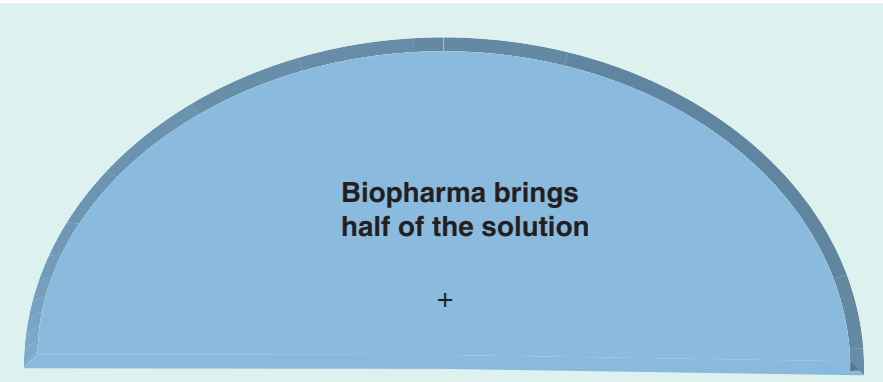

Partners needed for diagnostics knowledge and experience

- Research laboratory services

- Diagnostic developments

- Regulatory guidances

- Manufacturing
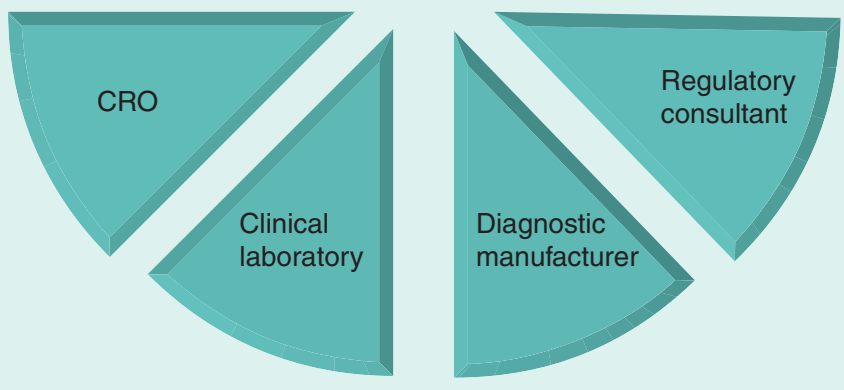

Figure 4. The traditional roles biopharmaceutical companies play in personalized medicine, if a contract research organization is used.

CRO: Contract research organizations.

discomfort with companion diagnostics directing their medical recommendations and treatment plans [111]. This can limit the financial success of the drug and its corresponding companion diagnostic, due to low usage.

Current diagnostic reimbursement policies do not support the development of high-value molecular tests [26], as reimbursement of these tests has typically been based on cost, not value (or potential value) [27].

Payers also may not support their use because they conclude that there is not enough evidence to prove efficacy. Despite the FDA's 2007 recommendation for genotyping for all patients being prescribed warfarin, in April 2009 the

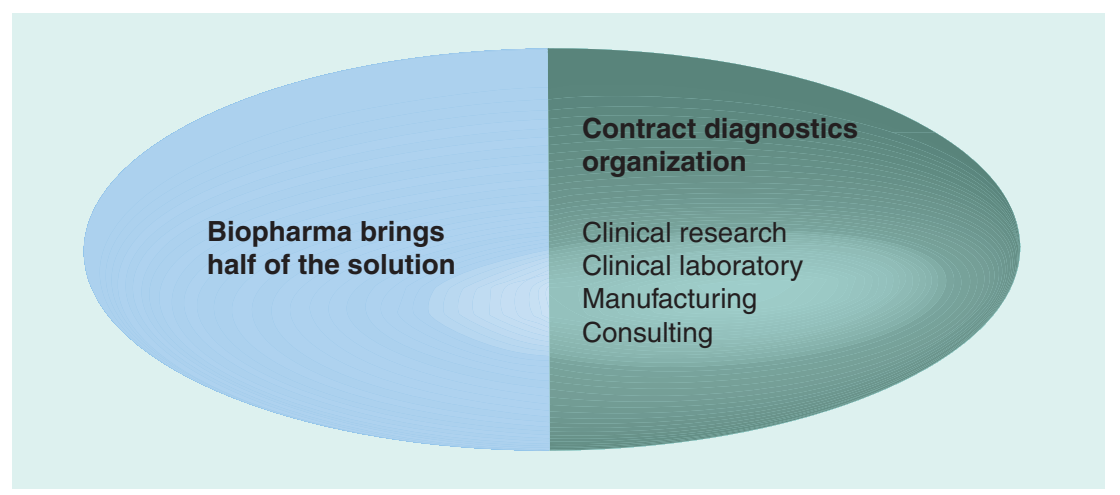

Figure 5 . Various services offered by an integrated partner, with all services housed within one organization.
US Centers for Medicare and Medicaid Services (CMS) decided not to routinely reimburse for companion diagnostics needed to help physicians correctly dose warfarin $[23,112,113]$. CMS claimed there was not enough evidence to prove that use of the tests improves patients' health [23]. Furthermore, some payers may not reimburse for a companion diagnostic even when it is recommended by a regulatory agency like the FDA, and have expressed doubts about the clinical usefulness of many companion diagnostics [23].

To overcome some of these issues, some authors have suggested that companies developing companion diagnostics use a strategy of royalties associated with the sales of the therapeutics their tests target [111].

Regulatory agencies can also be engaged to enhance personalized medicine development. It has been suggested that creating incentives comparable to the Orphan Drug Act for personalized medicines that target relatively small populations might boost development [23]. In addition, the FDA is attempting to coordinate and clarify the development process that manufacturers should follow, including delineating when a companion diagnostic must be approved before or concurrently with approval of the therapy [23] .

It has also been recommended that medical professional societies in corporate evidence-based testing in their clinical practice guidelines, which may facilitate the understanding and institutionalization of personalized medicine [23]. These can also help guide payers and help them gain confidence in personalized therapeutics, which will in turn, increase their development.

\section{- Logistical challenges}

Specialized scientific expertise is required from the initial steps in biomarker discovery, optimization, and through to validation. Few pharmaceutical companies have this expertise in house, therefore, outsourcing becomes necessary. Many major pharmaceutical companies including Roche, Pfizer, Merck, AstraZeneca, Bristol Myers Squibb, Amgen, Biogen and Eli Lilly have chosen, or needed, to partner with external companies to develop their own companion diagnostics [28]. Many of these companies have selected large partners in the diagnostics industry. While outsourcing has been necessary, doing so introduced several logistical challenges when coordinating the efforts of multiple partners. It also fragmented the process resulting in disorganization and miscommunications.

Overall, pharmaceutical companies must overcome several logistical complexities when 
managing and coordinating multiple partners in the process: research and development (initial research and biomarker development), a diagnostics company (to develop and possibly manufacture an assay kit), a CRO (to conduct validation trials), regulatory personnel and clinical laboratories (to perform assay validation and trial testing). All of these steps have the potential to result in product delay and introduce points of inefficiency (Figure 4).

One way for pharmaceutical companies to mitigate logistical challenges related to outsourcing is to bring key scientific expertise within their companies. However, significant time and resources are required on the scientific research and development side of personalized

\section{Executive summary}

\section{The promise \& power of personalized medicine}

- Stratified medicine can be more effective than traditional medicine.

- There are growing scientific, medical and economic interests in personalized medicine.

\section{Companion diagnostics \& how they impact personalized medicine}

- Companion diagnostics are critical to personalized medicine to ensure the effective, safe development and application of a personalized drug.

- Companion diagnostics can be used to diagnose, select treatment, dose treatment and monitor treatment of disease.

- Companion diagnostic development is challenging and requires specific expertise in several areas.

\section{Regulatory responses}

- Several regulatory guidances have either mandated or recommended that biomarker testing be performed prior to prescribing certain drugs.

- There are several companion diagnostics currently required by regulatory agencies.

\section{Developing a companion diagnostic}

- Efficiently introducing a successful personalized therapeutic to market requires codevelopment of the drug and its companion diagnostic.

- Regulatory agencies have attempted to describe the codevelopment process, but it is still rudimentary at best.

\section{Challenges to drug-diagnostic codevelopment}

- Traditional pharmaceutical companies have limited expertise in the development of companion diagnostics.

- Logistical challenges:

- Outsourcing becomes necessary, which disorganizes and fragments the process.

- Strategic business challenges:

- Traditional diagnostic partners may have conflicting motivations and business interests to their pharmaceutical partners.

- Regulatory challenges:

- Few contract research organizations have experience of in vitro diagnostics development, manufacturing and companion diagnostic validation trials.

- Financial challenges:

- Utilizing extensive new biologic tests in drug clinical trials increases the complexity and cost of the drug-development process.

- The number of late-stage compound failures is high; this makes a codevelopment agreement even less financially desirable.

- End users are not always comfortable with companion diagnostics directing their medical recommendations and treatment plans.

- Current diagnostic reimbursement policies do not support the development of such high-value tests.

\section{An integrated approach is the solution}

- A new, streamlined business model for codevelopment is necessary.

- The number of partners needs to be reduced, with each containing services in house.

- Services could include clinical research, clinical laboratory services, manufacturing and consulting.

\section{Conclusion}

- Companion diagnostics are necessary for personalized medicine, but not easy to develop.

- Regulatory agencies have weighed in and recommended drug-diagnostic codevelopment, although no effective process currently exists.

- Several challenges make the current codevelopment process very difficult, and more work is needed in this area.

- An integrated business model offers solutions to streamline the drug-diagnostic codevelopment process.

\section{Future perspective}

- Companion diagnostics will be increasingly critical to the success of personalized medicine in many medical specialties.

- Therapeutics and companion diagnostic codevelopment will continue to be a challenge, but will be mitigated by new paradigms such as the availability of integrated outsourcing options. 
therapeutics, potentially leading to several dead ends before success is achieved. As such, some pharmaceutical companies may find bringing expertise in house hard to justify. New business models are developing that offer this and other expertise in house, in efforts to partner with pharmaceutical companies seamlessly and reduce these logistical challenges.

\section{Integration is the solution}

As suggested by Cohen et al.: "To improve prospects for personalized medicine, more evidence is needed, but also better integration and codevelopment of drugs and companion diagnostics" [23]. Expeditious coordination of the drugdiagnostic codevelopment process requires a robust, lean and streamlined business model.

The number of partners in the process should be as few as possible. Ideally, all services (clinical research, clinical laboratory, manufacturing, consulting), could be contained within one organization. Scientific expertise in house can carry the process from biomarker discovery to clinical research, to clinical laboratory services, to manufacturing, and finally to the market. This allows the process to be objective, nimble and able to create any assay and follow the right regulatory pathway from the beginning. This business model is illustrated in Figure 5.

\section{Conclusion}

The combination of advances in molecular medicine, regulatory guidances, rational therapeutics use and the need for cost containment in healthcare is advancing the goal of true personalized medicine. Integral to the achievement of this objective will be the widespread implementation of companion diagnostics. The increasing importance of companion diagnostics and the need for codevelopment with therapeutics has many challenges. However, the application of new paradigms, such as flexible and integrated outsourcing options for companion diagnostics, will ensure a viable future for personalized medicine.

\section{Future perspective}

To date, the clearest advancement of personalized medicine has primarily been within the field of oncology. Companion diagnostics are critical to the future of personalized drug development, and the codevelopment process will be the focus of future regulatory guidances and studies. Although an understanding of the underlying molecular pathways in conditions such as neuropsychiatric disorders (e.g., Alzheimer's disease), endocrine disorders (e.g., diabetes) and cardiovascular disease is incomplete; future work is being done to identify challenges in these areas, to help further the application of personalized medicine in these fields [29].

In order for drug-diagnostic codevelopment to be successful, coordination between multiple agencies, stakeholders and groups will be essential. This requires successful relationships between those in public and private enterprises. In addition, ongoing communication between drug developers and regulatory agencies needs to occur to inform and progress regulatory guidance development.

Financial \& competing interests disclosure $P D$ Cotter and MW Moore are Principals at ResearchDx, LLC (CA, USA). The authors have no other relevant affiliations or financial involvement with any organization or entity with a financial interest in or financial conflict with the subject matter or materials discussed in the manuscript apart from those disclosed.

No writing assistance was utilized in the production of this manuscript.

\section{References}

Papers of special note have been highlighted as: " of interest

" of considerable interest

1 Papadopoulos N, Kinzler KW, Vogelstein B. The role of companion diagnostics in the development and use of mutation-targeted cancer therapies. Nature Biotechnol. 24(8), 985-995 (2006).

- General review of companion diagnostics in the oncology arena, circa 2006.

2 Langreth R, Waldholz M. New era of personalized medicine: targeting drugs for each unique genetic profile. Oncologist 4(5), 426-427 (1999).
3 Jorgensen JT. New era of personalized medicine: a 10-year anniversary. Oncologist 14(5), 557-558 (2009).

- - A retrospective on personalized medicine after a decade.

4 Jorgensen JT. A challenging drug development process in the era of personalized medicine. Drug Discov. Today 16(19-20), 891-897 (2011).

-1- Discusses several challenges in the personalized drug-development process affecting various aspects of medicine.

5 Becker R Jr, Mansfield E. Companion diagnostics. Clin. Adv. Hematol. Oncol. 8(7), 478-479 (2010).
6 Choi YL, Soda M, Yamashita Y et al. $E M L 4-A L K$ mutations in lung cancer that confer resistance to ALK inhibitors. N. Engl. J. Med. 363(18), 1734-1739 (2010).

7 Kwak EL, Bang YJ, Camidge DR et al. Anaplastic lymphoma kinase inhibition in non-small-cell lung cancer. $N$. Engl. J. Med. 363(18), 1693-1703 (2010).

8 Gerber DE, Minna JD. ALK inhibition for non-small cell lung cancer: from discovery to therapy in record time. Cancer Cell 18(6), 548-551 (2010).

9 Atherly AJ, Camidge DR. The cost-effectiveness of screening lung cancer patients for targeted drug sensitivity markers. Br. J. Cancer 106(6), 1100-1106 (2012). 
- Looks at the economic impact and potential of utilizing personalized medicine to treat lung cancer patients in the UK.

10 Ross DM, Hughes TP. Current and emerging tests for the laboratory monitoring of chronic myeloid leukaemia and related disorders. Pathology 40(3), 231-246 (2008).

11 Carlquist JF, Anderson JL. Using pharmacogenetics in real time to guide warfarin initiation: a clinician update. Circulation 124(23), 2554-2559 (2011).

- Discusses of the direct clinical applications of pharmacogenomics in warfarin dosing.

12 Rettie AE, Korzekwa KR, Kunze KL et al. Hydroxylation of warfarin by human cDNA-expressed cytochrome P-450: a role for P-4502C9 in the etiology of $(S)$-warfarin-drug interactions. Chem. Res. Toxicol. 5(1), 54-59 (1992).

13 Piccart-Gebhart MJ, Procter M, Leyland-Jones $\mathrm{B}$ et al. Trastuzumab after adjuvant chemotherapy in HER2-positive breast cancer. N. Engl. J. Med. 353(16), 1659-1672 (2005).

14 Romond EH, Perez EA, Bryant J et al. Trastuzumab plus adjuvant chemotherapy for operable HER2-positive breast cancer. N. Engl. J. Med. 353(16), 1673-1684 (2005).

15 Liu W, Zhong S, Chen J, Yu Y. HER-2/neu overexpression is an independent prognostic factor for intestinal-type and early-stage gastric cancer patients. J. Clin. Gastroenterol. 46(4), e31-37 (2012)

16 Rüschoff J, Hanna W, Bilous M et al. HER2 testing in gastric cancer. a practical approach. Mod. Pathol. 25(5), 637-650 (2012).

17 Lee B, Mukhi N, Liu D. Current management and novel agents for malignant melanoma. $J$. Hematol. Oncol. 5(1), 3 (2012).

18 Halait H, Demartin K, Shah S et al. Analytical performance of a real-time PCR-based assay for V600 mutations in the BRAF gene, used as the companion diagnostic test for the novel BRAF inhibitor vemurafenib in metastatic melanoma. Diagn. Mol. Pathol. 21(1), 1-8 (2012).

19 Davies H, Bignell GR, Cox C et al. Mutations of the $B R A F$ gene in human cancer. Nature 417(6892), 949-954 (2002)

20 Bollag G, Hirth P, Tsai J et al. Clinical efficacy of a RAF inhibitor needs broad target blockade in BRAF-mutant melanoma. Nature 467(7315), 596-599 (2010).

21 Thompson MA, Aberg JA, Cahn P et al. Antiretroviral treatment of adult HIV infection. 2010 recommendations of the International AIDS Society-USA panel. JAMA 304(3), 321-333 (2010).

22 Sierra S, Kaiser R, Lubke N et al. Prediction of HIV-1 coreceptor usage (tropism) by sequence analysis using a genotypic approach. J. Vis.Exp. (58), pii: 3264 (2011).
23 Cohen J, Wilson A, Manzolillo K. Clinical and economic challenges facing pharmacogenomics. Pharmacogenomics J. doi:10.1038/tpj.2011.63 (2012) (Epub ahead of print).

III Examines the clinical and economic challenges that are faced by developers of and payers for personalized drugs and companion diagnostics.

24 Soda M, Choi YL, Enomoto M et al. Identification of the transforming EML4-ALK fusion gene in non-small-cell lung cancer. Nature 448(7153), 561-566 (2007).

25 Rockoff JD. Tests are key but partners tricky. The Wall Street Journal, 30 August (2011).

26 Parkinson DR, Johnson BE, Sledge GW. Making personalized cancer medicine a reality: challenges and opportunities in the development of biomarkers and companion diagnostics. Clin. Cancer Res. 18(3), 619-624 (2012).

-11 Recent overview of strengths and weaknesses in companion diagnostic development, along with new areas of opportunity.

27 Conti R, Veenstra DL, Armstrong K, Lesko LJ, Grosse SD. Personalized medicine and genomics: challenges and opportunities in assessing effectiveness, cost-effectiveness, and future research priorities. Med. Decis. Making 30(3), 328-340 (2010).

- Discusses the current state of practice and research on personalized medicine in various fields, including challenges raised, potential approaches to meet these challenges and proposed directions for future work.

28 Pollack A. Gene test for dosage of warfarin is rebuffed. The New York Times, 4 May (2009).

29 Nikolcheva T, Jager S, Bush TA, Vargas G. Challenges in the development of companion diagnostics for neuropsychiatric disorders. Expert Rev. Mol. Diagn. 11(8), 829-837 (2011).

\section{Websites}

101 Personalized Medicine Coalition. Personalized medicine by the numbers (2006). www.personalizedmedicinecoalition.org/ sites/default/files/files/PM_by_the Numbers.pdf

102 Personalized Medicine Coalition. The Case for Personalized Medicine, Third Edition. (2011).

www.personalizedmedicinecoalition.org/sites/ default/files/files/Case_for_PM_3rd_edition. pdf

-11. Accessible summary of personalized medicine themes, goals and statistics, circa 2011.
103 Pricewaterhouse Coopers LLP. The new science of personalized medicine: translating the promise into practice. www.pwc.com/us/en/healthcare/ publications/personalized-medicine.jhtml

104 Tufts Center for the Study of Drug Development. Lack of clinically useful diagnostics hinder growth in personalized medicines. Impact Report 13(4), (2011). http://csdd.tufts.edu/files/uploads/ july-august_csdd_impact_report_press_ release.pdf

105 WarfarinDosing. www.warfarindosing.org

106 Commission E. Revision of Directive 98/79/ EC of the European Parliament and of the Council of 27 October 1998 on in vitro diagnostic medical devices. (2011). http://ec.europa.eu/health/medical-devices/ files/recast_docs_2008/ivd_pc_outcome_ en.pdf

107 Draft Guidance for Industry and Food and Drug Administration Staff - In vitro companion diagnostic devices (2011) www.fda.gov/downloads/MedicalDevices/ DeviceRegulationandGuidance/ GuidanceDocuments/UCM262327.pdf

III Most recent draft guidance from the US FDA on companion diagnostic development and the codevelopment process.

108 US FDA. Driving biomedical innovation: initiatives to improve products for patients (2011). www.fda.gov/downloads/AboutFDA/ ReportsManualsForms/Reports/ UCM274464.pdf

109 EMA. Reflection paper on co-development of pharmacogenomic biomarkers and assays in the context of drug development EMA/ CHMP/641298/2008 (2010). www.ema.europa.eu/docs/en_GB/ document_library/Scientific_ guideline/2010/07/WC500094445.pdf

110 Association of Clinical Research Organization. Fact sheet. www.acrohealth.org/fact-sheet.html

111 European Industrial Pharmacy. Krul KP. Challenges faced by companion diagnostics (2011). www.industrialpharmacy.eipg.eu/records/ EIP11/EIP11\%20Dec11\%20P17.pdf

112 Centers for Medicare and Medicaid Services. Decision memo for pharmacogenomic testing for warfarin response (CAG-00400N). www.cmms.hhs.gov/medicare-coveragedatabase/details/nca-decision-memo.aspx?N CAId $=224 \&$ NcaName $=$ Pharmacogenomic + Testing+for+Warfarin+Response $\&$ MEDCA CId $=47 \&$ NCDId $=333 \&$ ncdver $=1 \&$ IsPopup $=\mathrm{y} \& \mathrm{bc}=$ AAAAAAAAIAAA $\&$ 
113 Drug Discovery World. Naylor S, Cole T. Overview of companion diagnostics in the pharmaceutical industry.

www.ddw-online.com/s/personalisedmedicine/p92845/overview-of-companiondiagnostics-in-the-pharmaceutical-industryspring-10.html
114 US FDA. Table of pharmacogenic biomarkers in drug labels (2011). www.fda.gov/drugs/scienceresearch/ researchareas/pharmacogenetics/ ucm083378.htm

115 Tufts Center for the Study of Drug Development. Personalized medicine is playing a growing role in development pipelines. Impact Report 12, 6 (2010).

http://csdd.tufts.edu/files/uploads/nov-dec_ ir_report_summary.pdf

116 US FDA.

www.fda.gov

117 Age of personalized medicine.

www.ageofpersonalizedmedicine.org 